\title{
An Ant and a Man, a Rock and a Woman: Preliminary Notes toward an Alternate History of Chinese Worldviews
}

\author{
Robert Ford Campany
}

\section{An Ant and a Man}

Consider the following fifth-century anecdote. ${ }^{1}$ A man named Dong Zhaozhi was traveling by boat when he noticed a floating twig. On it, an ant scurried back and forth, seemingly afraid. So Dong brought the ant on board. That night he dreamed a black-robed man thanked him. "I am king among ants," the man said. "Should you ever find yourself in trouble, please let me know." Years later, Dong was falsely arrested. Recalling his dream, he gathered several ants and told them of his plight. He then dreamed again of the black-robed personage, who advised him to flee into the hills and await the official pardon coming by courier. Waking, he found that ants had chewed through his restraints, allowing him to escape. The pardon soon arrived.

Hundreds - or probably thousands - of stories like this one, about animalhuman (and insect-human) interactions, were exchanged and compiled in early medieval China. Many of them did not survive into the modern era, but enough did to constitute a formidable body of evidence. But: evidence of what? How should we understand such stories? Who are their subjects? Why were they recorded, collected, and disseminated? In this brief paper I will sketch a project that I intend to develop at much greater length elsewhere, a project in which these stories will furnish invaluable evidence.

Much of the history of animal-human relationships has been anthropocentric, focused on "the human cultural ... contexts for such relationships rather than on the emergent ... relationship itself." 2 I want to rethink stories like this

1 The work in question is QiXie's Records (QiXieji 齊諧記), compiled by Dongyang Wuyi 東陽 无疑 (fl. ca. 435). This story is translated in Robert Ford Campany, A Garden of Marvels: Tales of Wonder from Early China (Honolulu: Univ. of Hawaii Press, 2015), 24-25. For a listing of its multiple textual witnesses see p. 136. On Qi Xie ji see Campany, Strange Writing: Anomaly Accounts in Early Medieval China (Albany: State Univ. of New York Press, 1996), 8o-81.

2 Eduardo Kohn, "How Dogs Dream: Amazonian Natures and the Politics of Transspecies Engagement," American Ethnologist 34.1 (Feb. 2007): 18n2. 
one less anthropocentrically and more zoo-semiotically. My rethinking is informed by recent work in "anthropology of life" (Eduardo Kohn), revisionist rejections of the nature/culture binary (Philippe Descola), new animisms and the "ontological turn" (Irving Hallowell, Nurit Bird-David, Graham Harvey), "posthumanities" (Donna Haraway), biosemiotics (Jesper Hoffmeyer, Lynn Margulis), and theories of how selves and aims first emerged in an otherwise aimless universe (Terrence Deacon, Jeremy Sherman). Much of this in turn builds on the semiotics of Charles Peirce and others. For these researchers, life is defined by a single key characteristic: that all living things, from the simplest to the most complex, are selves with aims, selves that represent the world-often differently than humans do. Any dynamic in which "something ... stands to somebody for something in some respect or capacity" (to quote Peirce's definition of a sign ${ }^{3}$ ) is alive, and the "somebody" in this equation is some sort of self-but not necessarily a human one. Processes of sign interpretation, meaning, and intention do not distinguish culture from nature. Life is semiosis.

With these all too briefly sketched ideas in mind, let us return to the ant story, serving here as exemplar of a much larger set. We can see it as a story about a relationship. The relationship is built on the exchange of help in dire circumstances. It begins in an intersubjective encounter in which the human protagonist recognizes another self, a self that recognizes itself to be in trouble on the water. Significantly, some of the textual variants that have come down to us say that as it scurried to and fro the ant “feared for its life" 惶遽畏死; the ant thus becomes a narrative subject, a co-protagonist. Other variants put this as an inference in the mind and speech of Dong: "Zhaozhi said [to himself], “This means it is in fear for its life”" 昭之曰此畏死也; the ant is thus apprehended by the man, via what philosophers are wont to call a "theory of other minds," as a subject like himself, whose behavior evinces the aim to stay alive. Accustomed as we are to the fixity of texts that is a byproduct of printing technology, we might naturally assume that only one of these versions is the "original" and thus "correct" one. But in a manuscript culture such as that of early medieval China, where much more fluid views and treatments of texts were the norm, we should instead see each version that has come down to us as an artefact of social memory. Each bears witness to what some people claimed to have happened, or to the sort of thing people thought could happen. It's not a

3 As quoted and discussed in ibid., 6; idem, How Forests Think: Toward an Anthropology beyond the Human (Berkeley: Univ. of California Press, 2013), 29; and Jesper Hoffmeyer, Biosemiotics: An Examination into the Signs of Life and the Life of Signs, tr. Jesper Hoffmeyer and Donald Favareau (Scranton, Penn.: Univ. of Scranton Press, 2008), 20. 
question, then, of trying to ascertain which version was "original" or "correct," but of pondering the distinct implications of each. ${ }^{4}$

Let us think of this story, then, as bearing witness to the idea of a transspecies ecology of selves. ${ }^{5}$ (Whether the incident really occurred as reported is much less significant than the facts that many people thought it was the sort of thing that might possibly occur and that many parties joined in the laborious processes needed to secure its transmission into modern times.) Each party to the ecology recognizes the other as a member of a society with certain conventions. Although the man is initially unaware of the ant's status in its social world, he later, having learned of it, depends on it to make his own request for aid. And for his part the ant king is kept informed of human events by his far-flung network of formic subjects. This mutual recognition is what enables their exchange of help.

The two selves fall into a pattern of gifting that transcends species. ${ }^{6}$ This gifting is not a conceptual or merely cultural structure imposed by the human on the blank canvas of "nature" so much as an emergent feature of the interaction itself. The story invites us to consider whether, rather than the familiar binary in which cultures are plural but nature is singular, there is in fact one culture - in which forms like gift-giving link selves of diverse species—but many natures, in the sense of many Umwelten, many worlds-as-experienced depending on each species' distinctive capacities. ${ }^{7}$ We are, of course, accus-

For more on this point, see Campany, Signs from the Unseen Realm: Buddhist Miracle Tales from Early Medieval China (Honolulu: Univ. of Hawaii Press, 2012), 17-30, and works cited there.

5 In the sense developed in Kohn, "How Dogs Dream," and idem, How Forests Think.

6 Following Philippe Descola (Beyond Nature and Culture, tr. Janet Lloyd [Chicago: Univ. of Chicago Press, 2013], 307-35), I see the relationship here as one involving gifting, not exchange. "Unlike exchange, the gift is above all a one-way gesture that consists in abandoning something to someone without expecting any compensation other than that, possibly, of gratitude on the part of the receiver.... Reciprocal benefaction is never guaranteed where a gift is concerned" (p. 313). But I would add that in China the expectation of a commensurate return has often been stronger than Descola suggests. On the one hand, then, Dong's initial gesture was not done in the expectation of a return; but on the other hand, the ant king's response to it was, in Chinese context, hardly unexpected, either (except in the obvious way that he was an ant with extraordinary power to be of assistance).

$7 \quad$ On this concept, see the classic discussion in Jakob von Uexküll, $A$ Foray into the World of Animals and Humans, with A Theory of Meaning, tr. Joseph D. O'Neil (Minneapolis: Univ. of Minnesota Press, 2010), and the use made of it, for example, in Kohn, How Forests Think, 84, and Kohn, "How Dogs Dream," 4-5, 7, 9. "Because an organism is the locus of the work that is responsible for generating the constraints that constitute information about its world, what this information can be about is highly limited, specific, and self-centered. Like the treasure hunter with his metal detector, an organism can only obtain information about its environment that its internally generated dynamic processes are sensitive 
tomed to other readings. One might read the story as a charming projection of a uniquely human, perhaps "Confucian" value (that of bao 報 or moral reciprocity) onto the sign-less, value-less, self-less, aim-less nonhuman world of nature. In such a reading, the story would have only human beings and human culture to be about. Or one might simply read it as a precursor of "fiction," in which case it has only the prehistory of a literary genre and the supply of entertainment to be about. ${ }^{8}$ I am pursuing a different reading, one in which the narrative's two dream events are crucial.

For dreaming is a privileged mode of cross-kind communication, allowing the ant - normally presumably a user of indexical signs ${ }^{9}$ — to communicate in symbolic signs, that is, human language. ${ }^{10}$ That, we could say, is one affordance of dreaming. ${ }^{11}$ Another is the opportunity for the ant to appear in human form and garb. Selves come clothed in bodies, and in dreams (as well as in

to-von Uexküll's Umwelt, the constellation of self-centered species-relevant features of the world" (Terrence W. Deacon, Incomplete Nature: How Mind Emerged from Matter [New York: Norton, 2013], 410). See also Hoffmeyer, Biosemiotics, 171-211; Wendy Wheeler, The Whole Creature: Complexity, Biosemiotics and the Evolution of Culture (London: Lawrence \& Wishart, 2006), 120-22; and Alexandra Horowitz, Inside of a Dog: What Dogs See, Smell, and Know (New York: Scribner, 2009), 20-32.

8 Altogether too many studies of works of the zhiguai genre have been of this sort, due in part to the frequent isolation of the study of China's literary history from the study of its cultural and religious history.

9 Again, a sign, for Peirce, is "something which stands to somebody for something in some respect or capacity." Understood thus, "not all signs have languagelike properties, and ... not all the beings who use them are human" (Kohn, How Forests Think, 29). Peirce distinguished three general classes of signs. Icons are usually likenesses of their objects (e.g., photographs). Indexes, rather than being likenesses of the objects they represent, point to them (e.g., weathervanes as indices of wind direction). Symbols refer to their objects indirectly as a function of their systematic and conventional relationship to other symbols (e.g., words in a human language). "Unlike iconic and indexical modes of reference, which form the bases for all representation in the living world, symbolic reference is, on this planet at least, a form of representation that is unique to humans" (Kohn, How Forests Think, 31-32). See also Charles Peirce, The Essential Peirce: Selected Philosophical Writings, Volume 2 (1893-1913) (Bloomington, IN: Indiana University Press, 1998), 13-17, and James Jakób Liszka, A General Introduction to the Semeiotic of Charles Sanders Peirce (Bloomington: Indiana Univ. Press, 1996), 18-52.

Compare: "Dreaming is understood to be a privileged mode of communication through which, via souls, contact among beings inhabiting different ontological realms [that is, different Umwelten] becomes possible" (Kohn, "How Dogs Dream," 12).

On the notion of affordances as intended here, first developed by J. J. Gibson, see Caroline Levine, Forms: Whole, Rhythm, Hierarchy, Network (Princeton: Princeton Univ. Press, 2015), 6-11, and Nurit Bird-David, “'Animism' Revisited: Personhood, Environment, and Relational Epistemology," Current Anthropology 40, special issue 1 (February 1999): S6791. 
transformations, another ubiquitous motif of early medieval anecdotes) the clothing may be changed. ${ }^{12}$ Dong presumably would not have understood ant signs, but thanks to dreaming the ant king is able to meet him more than halfway, addressing him face to face in human form and speech.

It's crucial to note that it's not as if the ant was instantly recognized by the human protagonist as a self with aims because that's how Chinese people viewed its class of beings. In many situations an ant might have gone unnoticed. In others it might have been seen as an object, an instrument, or a nuisance. (In fact, yet another version of the story depicts other passengers on Dong's boat complaining about his bringing the ant aboard. ${ }^{13}$ ) But here, the ant's being seen as a self with aims emerges from the interaction of these two beings in their specific situation on the river. The ant scurries on the floating stick; the human being notices this behavior and situation, draws an inference about the ant's aims, and intervenes. It's not the intrinsic properties of either the ant or the human but rather, precisely, this pairing of human attention with the purposive behavior of the distressed ant that opens into a relationship that, facilitated by the communicative portal of dreaming, stretches over years. ${ }^{14}$

\section{A Rock and a Woman}

In his classic essay, "Ojibwa Ontology, Behavior, and World View," A. Irving Hallowell had this to say:

Since stones are grammatically animate, I once asked an old man: Are all the stones we see about us here alive? He reflected a long while and then replied, "No! But some are." This qualified answer made a lasting impression on me. And it is thoroughly consistent with other data that indicate that the Ojibwa are not animists in the sense that they dogmatically attribute living souls to inanimate objects such as stones. The hypothesis which suggests itself ... is that the allocation of stones to an animate grammatical category ... does not involve a consciously formulated

12 On the variability of the forms under which beings appear to people in dreams, see for example Robert Schweitzer, "A Phenomenological Study of Dream Interpretation among the Xhosa-Speaking People in Rural South Africa," Journal of Phenomenological Psychology 27.1 (1996): $72-96$.

13 These lines appear in the version preserved in the twentieth chapter of the received Soushen ji 搜神記; in one medieval anthology they are attributed to QiXieji. Cf. Bird-David, “'Animism' Revisited," 75 . 
theory about the nature of stones. It leaves a door open that our orientation on dogmatic grounds keeps shut tight. Whereas we should never expect a stone to manifest animate properties of any kind under any circumstances, the Ojibwa recognize, a priori, potentialities for animation in certain classes of objects under certain circumstances. The Ojibwa do not perceive stones, in general, as animate, any more than we do. The crucial test is experience. Is there any personal testimony available? 15

Hallowell goes on to recount several anecdotes in which Anishinaabe people ${ }^{16}$ saw stones move, or encountered stones with features suggesting eyes and a mouth, or saw stones opening their mouths as if to speak or disgorge objects. It is not, then, that the Anishinaabe "personify" non-human creatures or natural objects in general. For this would imply two things that are not the case: that at some point Anishinaabe people first saw them as inanimate, material things, and only later began "personifying" them, and that how they see them is entirely a function of their membership in general classes. It is, instead, a matter of encounters in particular situations, and of subsequent socially circulated testimony — stories—about such experiences. Similarly, concerning the hunter-gatherer Nayaka people of South India the anthropologist Nurit Bird-David writes:

My argument is that Nayaka focus on events. Their attention is educated to dwell on events. They are attentive to the changes of things in the world in relation to changes in themselves. As they move and act in the forest, they pick up information about the relative variances in the flux of the interrelatedness between themselves and other things against relative invariances. When they pick up a relatively changing thing with their relatively changing selves - and, all the more, when it happens in a relatively unusual manner-they regard as devaru [that is, as a "superperson"17]

Hallowell, "Ojibwa Ontology, Behavior, and World View," in Primitive Views of the World, ed. Stanley Diamond (New York: Columbia Univ. Press, 1964), 54-55, emphasis added. For an astute unpacking and appreciation of Hallowell's essay and its aims, see Pauline Turner Strong, "A. Irving Hallowell and the Ontological Turn," Hau: Journal of Ethnographic Theory 7.1 (2017), 468-72.

Switching to the autonym used by these indigenous people of what's now Canada and the northern United States.

Not, however, supernatural person. See Bird-David, “Animism' Revisited," 71, and Miguel Astor-Aguilera, "Maya-Mesoamerican Polyontologies: Breath and Indigenous American Vital Essences," in Rethinking Relations and Animism: Personhood and Materiality, ed. Miguel Astor-Aguilera and Graham Harvey (London: Routledge, 2018), 143, as over against Roger Ivar Lohmann, "The Supernatural is Everywhere: Defining Qualities of Religion in 
this particular thing within this particular situation. This ... arises from the stories which Nayaka tell. ${ }^{18}$

With these points in mind, consider now a Chinese anecdote about a human being and a stone. Among the tales collected in Arrayed Accounts of Marvels (Lieyi zhuan 列異傳), attributed to Cao Pi 曹丕 (187-226), we find:

A woman of the Dai clan in Yuning who had long been ill once went outdoors and, noticing a small stone, said to it, "If you have divinity and can cure my illness, I will worship you." That night she dreamed of a personage who said, "I am about to bestow blessings on you." Afterwards she gradually recovered. So she established a shrine for the deity, calling it the Shrine of the Stone Marquis. ${ }^{19}$

We are not told why the woman "notices" 見 the particular stone in question, only that she does. We sense a bit of weight hanging on "went outdoors" 出, perhaps implying that Ms. Dai had been shut in for a long time and that it was on this rare excursion that the stone caught her attention. In any case, here again it's not as if this lady is depicted as acting on a general cultural belief that stones are living beings who can cure ailments. Nor (I think) does the story wish to argue that just any object at all, if approached in this manner, would respond as this stone does. Rather, this particular stone catches her gaze and she responds by focusing her attention and intention on it, promising to serve it ritually if it possesses divine power and can cure her. This recognition and promise open the portal of a relationship, each party responding in turn to the other. She talks with the stone, and this

"talking with" stands for attentiveness to variances and invariances in behavior and response of things in states of relatedness and for getting to know such things as they change through the vicissitudes over time of the engagement with them. To "talk with a [stone]" ... is to perceive what it does as one acts towards it, being aware concurrently of changes in oneself and the [stone]. It is expecting response and responding, growing into mutual responsiveness and ... possibly into mutual responsibility. ${ }^{20}$

Melanesia and Beyond," Anthropological Forum 13 (2003), 175-85. One of the arguments of the project I'm sketching here will be that the ways in which scholars routinely use "supernatural" to characterize beings or aspects of Chinese religions is a category mistake. 
In her dream the stone appears as a personage $人$ declaring the intention to play its role in this emergent relationship. Again, dreaming is a key portal of communication, affording non-human selves the capacity to appear in human form and speak human language. The woman's recovery is taken as evidence that this intention was fulfilled, and she follows through by establishing the shrine. That the site acquired a name suggests that it came to be frequented by other people, gaining a local reputation. It is telling that the stone never confirms (or denies) its possession of divine power. We are left to wonder whether it was the interaction between the two parties that performed the stone's divinity into being. In other words, rather than see its divine power either already existing independently of the woman's response to it or as resulting from her sheer projection of power onto a "dumb object,"21 we are invited to think of "divinity" here as a type or aspect of the relationship between the two parties, co-activated and sustained precisely by their interactions and in no other way. ${ }^{22}$

Another version of this little anecdote has come down to us, attributed to Gan Bao's 干寶 early fourth-century Inquest into the Spirit Realm (Soushen ji 搜神記). I italicize details that differ importantly from the Lieyi zhuan version:

A woman of the Dai clan in Yuzhang had long suffered from an incurable illness. She [once] noticed a small stone with the form of a human being 形像偶人. She told it: "You have human form 爾有人形. Are you divine? If you are able to cure my affliction, I will treat you very generously." That night she dreamed of a personage who said, "I am about to bestow blessings on you." Afterwards she gradually recovered from her illness. So she built a shrine at the foot of a mountain. Members of the Dai clan served as the mediums there 戴氏爲巫, so it came to be known as the Shrine to Marquis Dai. ${ }^{23}$

This version supplies a reason why the woman noticed this particular stone: it jumped out at her because of its unusual human-like form, a form that she took as hinting at its potential. (This motif of the striking object is a staple in Western thought experiments on how the phenomenon known as "religion" might first

21 Marshall Sahlins, How "Natives" Think: About Captain Cook, For Example (Chicago: Univ. of Chicago Press, 1995), 153.

There were stories circulating in this period, a few of which have survived, which can be read as suggesting precisely this. See Robert Ford Campany, "Religious' as a Category: A Comparative Case Study," Numen 65 (2018): 363-66.

23 The story appears in the fourth chapter of the received twenty-chapter arrangement of Soushen ji. 
have emerged. ${ }^{24}$ ) The human form that the stone assumes in the woman's dream is here simply an extension of how it appeared to her in waking experience. Here, members of the woman's family go on to serve as the mediums attached to the shrine - that is, as the literal mouthpieces through whom the god (or, to be more precise, the being who was being treated by the Dai clan and other locals as what in English is termed a "god") spoke to human audiences. Whether through the portal of dreams or the bodies of mediums, this stone had words to speak in response (and only in response) to human devotional vows and action.

The tenth-century geographic compendium Taiping huanyu ji 太本寰宇記 in turn attributes a slightly different version of this anecdote to Soushen ji. There, the chronically ill woman of the Dai clan had ventured out in search of medicines 覔藥 (presumably herbs in the wild) when she "noticed a stone standing erect and resembling human form" 見一石立似人形. She "paid courtesies to it" 禮之 and then spoke to it in terms similar to the above versions. So here the stone grabs the woman's attention both for its anomalous, human-like bodily form and for its erect stance. And she responds, as above, by engaging it as a fellow self, but here with the added mention of courtesies-a culturally patterned response, to which the stone responds in accordance with the pattern, both of them falling into a form. ${ }^{25}$

Finally, one other version of the tale is close to the Lieyi zhuan version - but adds a postscript. After the Shrine of the Stone Marquis is established, this early seventh-century text continues:

Later, someone took the stone and threw it into a fire. Everyone said, “This is a divine stone 此神石. You ought not commit such an offense against it." The man said, “What 'divinity' is this stone? 此石何神”. With that, he threw it into a well, [saying] "If it's really divine, then it should emerge from the well” 神當出井中. Next morning when everyone went to look, the stone had indeed emerged. The man who had seized it fell ill and died. ${ }^{26}$

This version's sponsors were unwilling to simply "leave the door open," as Hallowell's Anishinaabe interlocutors had been content to do. By setting a test and having the stone-person pass it, they added narrative confirmation of the

\footnotetext{
24 See Campany, "Religious' as a Category," 346-49.

25 Taiping huanyuji (Taipei: Wenhai chubanshe, 1963), 106.8b.

26 Beitang shuchao 北堂書鈔 (1888 ed.; rpt. Taipei: Wenhai chubanshe, 1962), 160.17a-b, attributing the text to Liexian zhuan 列仙傳, obviously an error for Lieyi zhuan 列異傳.
} 
stone's divinity. This version also affords us an unmistakable glimpse of the community of estimation involved in bringing the shrine cult to life. The shrine has become a site where multiple individuals engage in relationships with the stone and each other-mutual responsiveness and mutual responsibility.

\section{Conclusion}

Taking these sorts of stories seriously as products of collective worldviews and widespread patterns of narration and action would require considerable revision to our standard picture of early and medieval Chinese worldviews. We are accustomed to prioritizing such passages as this famous Xunzi 荀子 (3rd-century $\mathrm{BC}^{27}$ ) one depicting a human-crowned hierarchy of life:

Water and fire have qi but are not alive 無生. Grasses and trees are alive but are without awareness 無知. Birds and beasts have awareness but are without a sense of rightness 無義. Human beings have qi, are alive, and have awareness, and moreover they have a sense of rightness. This is why they are valued over all else in the world. ${ }^{28}$

Such "What a piece of work is man!" declarations are the staple of histories of Chinese "thought." On them, Ted Slingerland comments: "The picture that emerges ... of pre-Qin Chinese texts is that consciousness and the ability to think and choose, centered in the xin 心 [the mind or heart], is what makes a person a person, rather than an animal or inert object." ${ }^{29}$ But notice that, by these lights, stories showing animals possessing consciousness, memory, the ability to think and choose, and a sense of fairness, are portraying animals as persons, too-just not human persons. The anecdotes may be read as evidence of a more expansive ecology of selves, and a more relational way of knowing within such an ecology, than that envisioned in Xunzi and similar texts.

If we were to take up a broad enough archive of texts, expanding our engagement beyond the small circle of works conventionally deemed "philosophical,"

27 The text was assembled by Liu Xiang 劉向 (77-6 в СE) from earlier bits; how much earlier is hard to say.

28 Xunzi jijie 荀子集解, ed. Wang Xianqian 王先謙 (1842-1918) (Beijing: Zhonghua shuju, 1988), 5 (sect. 9).164. Adapting the translations in Eric L. Hutton, Xunzi: The Complete Text (Princeton: Princeton Univ. Press, 2014), 76, and Edward Slingerland, Mind and Body in Early China: Beyond Orientalism and the Myth of Holism (New York: Oxford Univ. Press, 2019), 112.

29 Slingerland, Mind and Body, 111. 
I think we'd see that this more variegated ecology of selves was at least as prevalent as the utterly human-centered view reflected in the Xunzi passage and privileged in much discourse both in and about China. This is not the place to develop that big-picture argument. But I want to emphasize that this ecology and epistemology were not just convenient narrative devices imposed on an extra-textual life-world to which they were alien. How do I know this? I know it because each of these stories emerged from lived experience. Each was circulated, retold, written, rewritten, compiled by countless individuals with some interest in it. Each telling, writing, or reading of the story performed an ecology of relationship that was at least entertained as possible - as imaginable - by many persons. My claim is not that any given anecdote accurately reports what happened but that it preserves for us what some thought had happened, thought it possible to have happened, and wished others to believe had happened. In a manuscript culture, each recorded and transmitted anecdote is an artefact of collective memory in the most literal sense, representing an investment of time and resources on the part of many persons. Each of these anecdotes was preserved in the archive for the same reason: each won sponsors.

In 1878, Friedrich Nietzsche published a famous aphorism reminiscent of Edward Burnett Tylor's equally famous thought-experiment (published in 1871) on the origins of what Tylor had termed "animism":

Misunderstanding of the dream (Mißverständnis des Traumes).- The man of the ages of barbarous primordial culture (der Mensch in den Zeitaltern roher uranfünglichen Kultur) believed that in the dream he was getting to know a second real world (eine zweite reale Welt): here is the origin of all metaphysics (der Ursprung aller Metaphysik). Without the dream one would have had no occasion to divide the world into two (... zu einer Scheidung der Welt gefunden)....

Nietzsche and Tylor, setting themselves against this imagined primordial humanity, were certain that there is only one Welt. For many Chinese people, I would argue, it was not that there were two worlds, the non-waking one a metaphysical deduction from dream experience- - a faulty deduction, by Nietzsche's and Tylor's reckonings. Rather, there were many Umwelten, many worlds-as-experienced by extra-human persons who were, like us, selves with aims. But the many Umwelten were linked by portals allowing for the transformation of beings, for communication in speech, for giving gifts and requesting help and many other interactions. Dreaming was perhaps the most important such portal. Dreaming was, among other things, a key component in a 
relational epistemology in which knowledge was a function of interactions and relations with other beings. In the common space of dreaming, women and men found themselves connected in relationships with a rich array of fellow sign-making, sign-interpreting selves - even, sometimes, an ant or a stone. 